\title{
VISUALIZING CHEMICAL REACTIONS WITH X-RAYS
}

\author{
S. BRATOS, ${ }^{1}$ M. WULFF, ${ }^{2}$ J.-CL. LEICKNAM, ${ }^{1}$ R. VUILLEUMIER, ${ }^{3}$ \\ X. ROZANSKA ${ }^{4}$
}

\author{
${ }^{1}$ Laboratoire de Physique Théorique de la Matière Condensée, \\ Université Pierre et Marie Curie \\ (Case Courrier 121, 4 Place Jussieu, 75252 Paris Cedex 05, France) \\ 2 European Synchrotron Radiation Facility \\ (BP 220, 38043 Grenoble Cedex, France) \\ ${ }^{3}$ Ecole Normale Supérieure, Département de Chimie \\ (24 rue Lhomond, 75231 Paris Cedex, France) \\ ${ }^{4}$ Materials Design SARL \\ (18 Rue de Saisset, 92120 Montrouge, France)
}

\begin{abstract}
The recombination of laser-dissociated iodine molecules dissolved in $\mathrm{CCl}_{4}$ is explored by time-resolved x-ray diffraction. The x-ray pulses employed in our experiments were generated by the ESRF synchrotron in Grenoble. The solvent contribution to the measured signals was eliminated using appropriate experimental procedures. Motions of iodine atoms were then studied from 200 ps to 10 ps. Different relaxation processes are shown to operate in this time domain. It is proved that the iodine recombination follows two reaction paths, taking place in the electronic states $\mathrm{X}$ and $\mathrm{A} / \mathrm{A}^{\prime}$ of $\mathrm{I}_{2}$, respectively. In spite of widely different experimental approaches, laser optical and x-ray studies provide a similar picture of this prototype reaction.
\end{abstract}

\section{Introduction}

Monitoring the temporally varying molecular structures during a chemical reaction represents a great challenge. Two major methods are employed in this domain. The first is time-resolved optical spectroscopy, which captures the corresponding ultrafast energy changes [1]. This method is very efficient and permits one to scan variations of the molecular energy during the process under consideration. However, extra information is required to link experimental frequencies and molecular geometry. The second method includes time-resolved x-ray diffraction and absorption. Since the wavelength of the x-rays is comparable to interatomic distances in molecules, this allows one to visualize atomic motions during a chemical reaction, directly and without any intermediate [2-4]. Large scale installations such as synchrotrons or linear accelerators are required in this field.

Time-resolved x-ray diffraction is a very powerful technique. Its power can be illustrated on a few examples. One of them is a study of a myoglobin $(\mathrm{Mb})$ mutant, explored with 150-ps x-ray pulses [5]. Another example refers to human haemoglobin, examined by wide angle $\mathrm{x}$-ray diffraction [6]. This technique was also applied to the study of some prototype chemical reactions. The recombination of photo-dissociated $\mathrm{I}_{2}$ in liquid $\mathrm{CCl}_{4}$ solutions was explored in this way, and atomic motions were visualized in real time $[7,8]$. However, this last study was limited to a time domain between $10 \mu$ s and 200 ps. We thus decided to extend this study to shorter times between $200 \mathrm{ps}$ and $10 \mathrm{ps}$. The new results reached in this way are presented in this paper. They are largely compatible with those provided by ultrafast optical spectroscopy.

\section{Experiment}

\subsection{Generalities}

The principle of our experiment is as follows [9]: we start by exciting a dilute $\mathrm{I}_{2} / \mathrm{CCl}_{4}$ solution by picosecond optical laser pulses. This generates a mixture of the electronic states $\mathrm{A}, \mathrm{A}^{\prime}$, and ${ }^{1} \pi_{u}$, which mainly dissoci- 


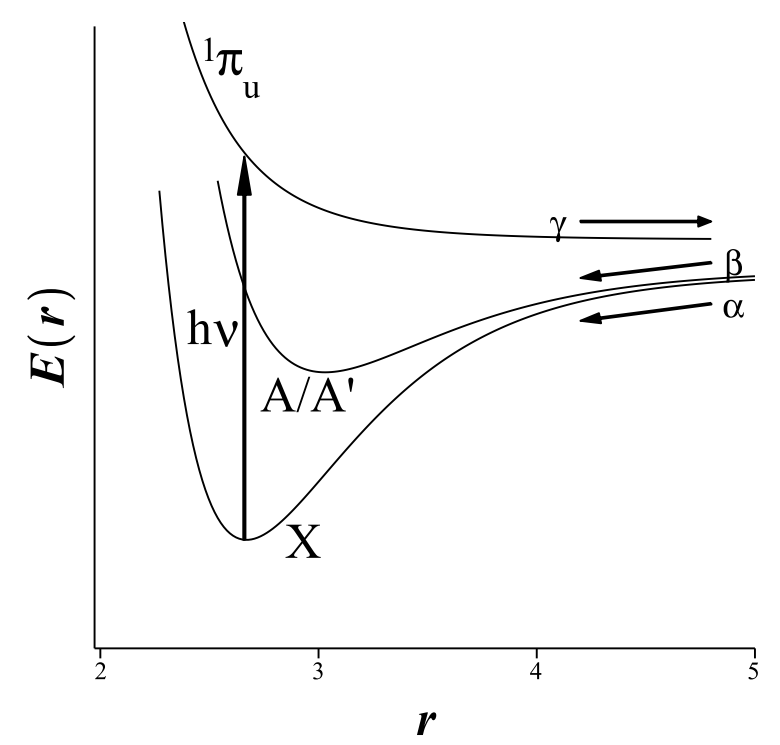

Fig. 1. Low-lying electronic states $\mathrm{X}, \mathrm{A} / \mathrm{A}^{\prime}$, and ${ }^{1} \pi_{u}$ of $\mathrm{I}_{2}$. The states $\mathrm{X}$ and $\mathrm{A} / \mathrm{A}^{\prime}$ are attractive, whereas the state ${ }^{1} \pi_{u}$ is repulsive. Here, $\alpha$ and $\beta$ represent the geminate recombination of two $\mathrm{I}$ atoms in $\mathrm{X}$ and $\mathrm{A} / \mathrm{A}^{\prime}$ respectively, whereas $\gamma$ represents the non-geminate recombination though the solvent

ate into ground state atoms (Fig. 1). The states A, $\mathrm{A}^{\prime}$ are closely spaced and can be viewed as a single electronic state $\mathrm{A} / \mathrm{A}^{\prime}$. Hot iodine molecules $\mathrm{I}_{2}^{*}$ with a "bond length" $R_{0} \approx 4.5 \AA$ are formed in the solvent cage in less than 1 ps. Then they transform into either $\mathrm{I}_{2}^{*} \rightarrow \mathrm{I}_{2}$ or $\mathrm{I}_{2}^{*} \rightarrow 2 \mathrm{I}$. Only the first of these processes is fast enough to be considered here; it can be realized in two different ways. ( $i$ ) The relaxation of $\mathrm{I}_{2}^{*}$ is along the $\mathrm{X}$ state potential. The time $\tau_{\alpha}=150 \mathrm{ps}$ is characteristic of this process called vibrational cooling. (ii) The relaxation of $\mathrm{I}_{2}^{*}$ is along the $\mathrm{A} / \mathrm{A}^{\prime}$ potential. The atoms reach the bottom of this energy surface very rapidly, in times $\tau_{\beta}<10$ ps. They remain trapped there for the rest of our experiment. These processes are explored here using time-resolved x-ray diffraction.

Several sorts of $\mathrm{x}$-ray signals are employed in this field. The signal $\Delta S(q, \tau)=S(q, \tau)-S(q)_{\text {eq }}$ describes the energy flux $S(q, \tau)$ scattered in a solid angle in the presence of a pump minus the equivalent quantity $S(q)_{\text {eq }}$ measured in its absence; here, $q$ is the scattering wave vector, and $\tau$ the pump-probe time delay. The signal $\Delta S_{\text {inst }}(q, t)=S_{\text {inst }}(q, t)-S(q)_{\text {eq }}$ differs from $\Delta S(q, \tau)$ in that the incident x-ray pulse is supposed to be very short; $t$ is then the time elapsed after the laser excitation. Finally, $\Delta S[r, \tau]$ and $\Delta S_{\text {inst }}[r, t]$ are Fourier sine transforms of $\Delta S(q, \tau)$ and $\Delta S_{\text {inst }}(q, t)$, respectively. The signal $\Delta S_{\text {inst }}[r, t]$ is particularly important. It is ex- pressible in terms of atom-atom distribution functions $g_{\mu, \nu}(r, t)$, where $r$ is the distance between the atoms $\mu$ and $\nu$. This signal thus provides information about how the geometry of a system varies during a chemical reaction.

\subsection{Technical details}

The experiments were done on beamline ID09B at the European Synchrotron Radiation Facility in Grenoble. This beamline provides a quasimonochromatic x-ray source with intense $\mathrm{x}$-ray pulses with a relative bandwidth of $3 \%$. A $1-\mathrm{kHz}$ femtosecond laser was used to dissociate iodine, and a chopper was used to reduce the $\mathrm{x}$-ray frequency to $1 \mathrm{kHz}$ (see Fig. 2). The sample was injected into the laser/x-ray beam by a laminar jet, and the scattering was recorded on an integrating CCD detector with fast readout. A single-harmonic undulator with a magnetic period of $17 \mathrm{~mm}$ provided an intense quasimonochromatic beam with a $3 \%$ bandwidth around $18.15 \mathrm{keV}$ with $5 \times 10^{8}$ photons per pulse. The experiment was performed in the 16-bunch mode with 100 ps $\mathrm{x}$-ray pulses. The exposure time per image was about 2 $\mathrm{s}$, and 1200 scattering images were taken per hour. The images were integrated azimuthally and were corrected for the polarization and space-angle effects. Optical excitation was realized with 0.5 -ps laser pulses at $530 \mathrm{~nm}$, a wavelength where the $\mathrm{I}_{2}$ absorption in $\mathrm{CCl}_{4}$ attains its maximum. Finally, the $\mathrm{I}_{2} / \mathrm{CCl}_{4}$ solution was injected into the beams using a sapphire nozzle producing a $0.3-$ mm-thick sheet of liquid. Its speed was adjusted to inject a fresh sample for every new x-ray pulse. For more complete information concerning instrumental problems, compare with Ref. [10].

An additional precaution was taken in our experiments. In order to study the iodine recombination dynamics in all possible details, the diffraction background of the pure $\mathrm{CCl}_{4}$ solvent was subtracted from that of the $\mathrm{I}_{2} / \mathrm{CCl}_{4}$ solution [11]. However, a complication arises when a chemical reaction takes place. The solvent changes its temperature which contributes an unwanted thermal background in $\Delta S(q, t)$. A second experiment was thus performed to evaluate this effect. The solution was treated transiently with shorter 0.1 -ps pulses at another wavelength of $390 \mathrm{~nm}$, to heat the solvent through multiphoton absorption without inducing any chemical change. Once the thermal response of the solvent was known, it was subtracted from the $\mathrm{I}_{2} / \mathrm{CCl}_{4}$ signal by a suitable scaling. 


\section{Theory}

\subsection{Basic considerations}

The theory underlying the present work is a statistical theory for time-resolved x-ray diffraction [12]. The electromagnetic fields are treated using Maxwellian electrodynamics, and the molecular system is described by quantum mechanics. This theory takes a simpler form in the present case due to the time-scale separation of the ultrafast optical and relatively slow chemical processes. In spite of this simplification, some approximations are still necessary. In fact, only electronic degrees of freedom are considered quantum-mechanically, whereas the others were assumed to be classical. None of these assumptions is believed to be restrictive.

A specific feature of the present problem is that some processes studied here are fast as compared with the duration of probing x-ray pulses. The observed signal is then distorted by the measuring device, and this distortion must be taken into account. In fact, the ideal signals $\Delta S_{\text {inst }}[r, t], \Delta S_{\text {inst }}(q, t)$, and the measured signals $\Delta S[r, \tau], \Delta S(q, \tau)$ are related to one another by the relations [12-14]:

$$
\begin{aligned}
& \Delta S(q, \tau)=\int d t I_{x}(t-\tau) \Delta S_{\mathrm{inst}}(q, t), \\
& \Delta S[r, \tau]=\int d t I_{x}(t-\tau) \Delta S_{\mathrm{inst}}[r, t],
\end{aligned}
$$

where $I_{x}(t)$ is the incident x-ray intensity. The above integrals are called convolution integrals; they must be evaluated to connect theory and experiment. In our work, the functions $\Delta S_{\text {inst }}[r, t], \Delta S_{\text {inst }}(q, t)$ are determined theoretically and are checked comparing their convolution with the experimental $\Delta S[r, \tau], \Delta S(q, \tau)$. Some details are given below.

\subsection{Model calculations}

The subsequent calculations are based on the following model: (i) Only the electronic states $\mathrm{X}$ and $\mathrm{A} / \mathrm{A}^{\prime}$ intervene in the $\mathrm{I}_{2}$ recombination [9]. (ii) The distribution functions $g_{\mathrm{X}}(r, t)$ and $g_{\mathrm{A} / \mathrm{A}^{\prime}}(r, t)$ in a diluted solution are simple Gaussians, centered at the instantaneous I-I distances $r_{0 \mathrm{X}}+\Delta r_{\mathrm{X}}(t)$ and $r_{\mathrm{A} / \mathrm{A}^{\prime}}+\Delta r_{\mathrm{A} / \mathrm{A}^{\prime}}(t)$. Here, $r_{0 \mathrm{X}}$ and $r_{0 \mathrm{~A} / \mathrm{A}^{\prime}}$ denote the equilibrium I-I lengths, and $\Delta r_{\mathrm{X}}(t)$ and $\Delta r_{\mathrm{A} / \mathrm{A}^{\prime}}(t)$ stand for their laser-induced increments. (iii) Interatomic I-I potentials are all assimilated to the Morse potentials. (iv) Iodine atoms stick a relatively long time at the turning points of the I-I

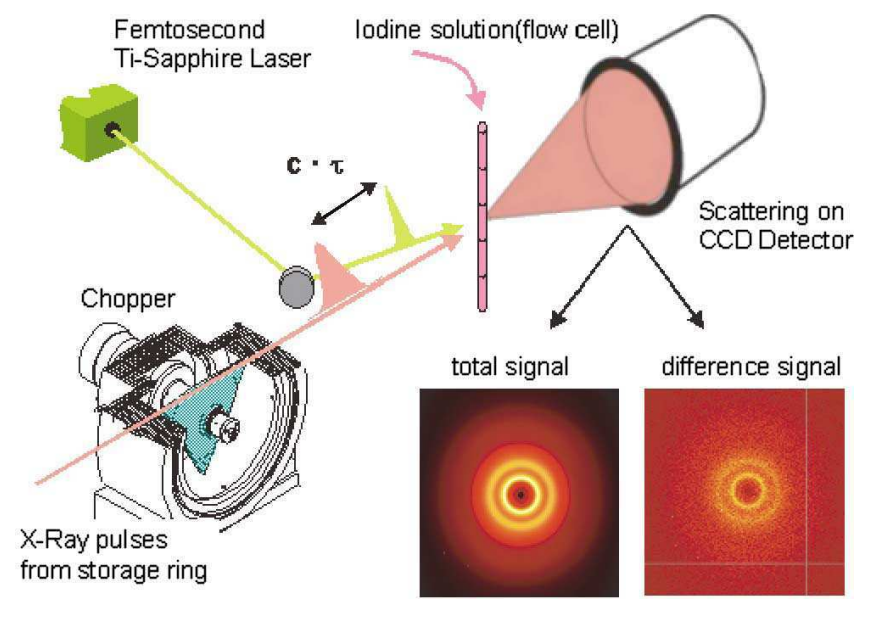

Fig. 2. Schematic illustration of the experimental set-up employed in the present x-ray diffraction experiments. The x-rays pulses are generated by an undulator. The spectrum is centered at $0.67 \AA$ and its band width is $d \lambda / \lambda=0.03$

potential [12]. This can be pictured assuming the existence of two molecular species. "Small" molecules are sticking the left turning point of these potentials, and "large" molecules are sticking their right turning point. This model is sufficient to interpret our experiments.

Some mathematical details complete the description. The potential of a Morse oscillator has the form $U(\Delta r)=$ $D[1-\exp (-b(\Delta r))]^{2}$, where $U$ is its energy and $\Delta r=$ $r-r_{0}$ its elongation. It also depends on the dissociation energy $D$ and on a parameter $b$. This parameter is related to the fundamental frequency of this oscillator by the relation $\omega^{2}=(2 D / \mu) b^{2}$, where $\mu$ is the reduced mass. Our Morse oscillator is supposed to be in contact with the thermal bath; its energy $U$ thus decays with time. Then, putting $U=U(t)=U_{0} \exp \left(-t / \tau_{v}\right)$, one finds easily

$U(\Delta r)=D[1-\exp (-b(\Delta r))]^{2}$

$\Delta r_{ \pm}=-(1 / b) \ln (1 \pm \sqrt{U / D})$

$U(t)=U_{0} \exp \left(-t / \tau_{v}\right)$,

$\Delta r(t)_{ \pm}=-(1 / b) \ln \left[1 \pm \sqrt{U_{0} / D} \exp \left(-t / 2 \tau_{v}\right)\right]$

The positive sign corresponds to the "small" molecule and the negative sign to the "large" molecule. The Morse potentials turn out to be sufficient to describe our experiments.

We are now in measure to present the final expression for $\Delta S_{\text {inst }}[r, t]$. It is obtained by inserting these 


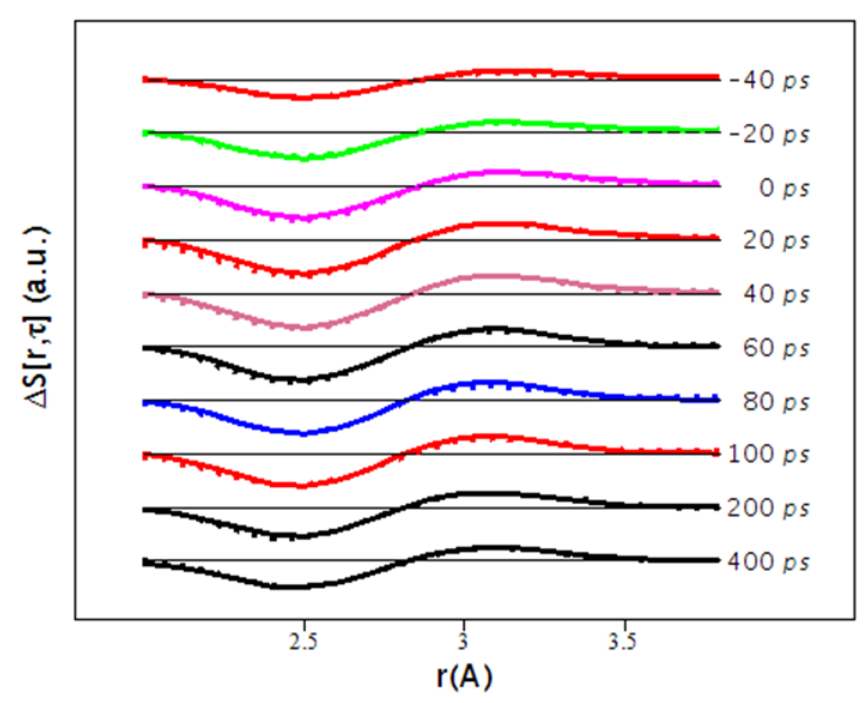

Fig. 3. Time-resolved x-ray signals $\Delta S[r, t]$. They are plotted as functions of the I-I distance $r$ and time delays $t$ from -40 to 400 ps. The points represent the experimental data, and the full curves are theoretical. These signals vary with time, but no peak shifts are observed

formulas for $\Delta r(t)_{ \pm}$into the distribution functions $g_{\mathrm{X}}$ $\left[r_{0 \mathrm{X}}+\Delta r_{\mathrm{X}}(t)\right]$ and $g_{\mathrm{A} / \mathrm{A}^{\prime}}\left[r_{0 \mathrm{~A} / \mathrm{A}^{\prime}}+\Delta r_{\mathrm{A} / \mathrm{A}^{\prime}}(t)\right]$. As the present model attributes to $g_{\mathrm{X}}(r, t)$ and $g_{\mathrm{A} / \mathrm{A}^{\prime}}(r, t)$ a Gaussian form, four expressions of the form Aexp [ $\left.a\left(r-r_{0}-\Delta r(t)\right)^{2}\right]$ are generated. Two of them correspond to the "small" $\mathrm{I}_{2}$ molecule in its electronic states $\mathrm{X}$ and $\mathrm{A} / \mathrm{A}^{\prime}$; and the two others correspond to the "large" $\mathrm{I}_{2}$ molecule in the same electronic states $\mathrm{X}$ and $\mathrm{A} / \mathrm{A}^{\prime}$. As a consequence, we have

$$
\begin{aligned}
& \Delta S_{\mathrm{inst}}[r, t] / \text { Const }=\left[\xi \exp \left(-a_{\mathrm{X}}\left(r-r_{\mathrm{X} 0}-\Delta r_{\mathrm{X}(+)}(t)\right)^{2}\right)+\right. \\
& +(1-\xi) \exp \left(-a_{\mathrm{X}}\left(r-r_{\mathrm{X} 0}-\Delta r_{\mathrm{X}(-)}(t)\right)^{2}\right)- \\
& \left.-\exp \left(-a_{\mathrm{X}}\left(r-r_{\mathrm{X} 0}\right)^{2}\right)\right]+\left(n_{\mathrm{A} / \mathrm{A}^{\prime}} / n_{\mathrm{X}}\right)\left[\xi\left(A_{\mathrm{A} / \mathrm{A}^{\prime}} / A_{\mathrm{X}}\right) \times\right. \\
& \times \exp \left(-a_{\mathrm{A} / \mathrm{A}^{\prime}}\left(r-r_{\mathrm{A} / \mathrm{A}^{\prime} 0}-\Delta r_{\mathrm{A} / \mathrm{A}^{\prime}(+)}(t)\right)^{2}\right)+ \\
& +(1-\xi)\left(A_{\mathrm{A} / \mathrm{A}^{\prime}} / A_{\mathrm{X}}\right) \times \\
& \times \exp \left(-a_{\mathrm{A} / \mathrm{A}^{\prime}}\left(r-r_{\mathrm{A} / \mathrm{A}^{\prime}}+\Delta r_{\mathrm{A} / \mathrm{A}^{\prime}(-)}(t)\right)^{2}\right)- \\
& \left.-\exp \left(-a_{\mathrm{X}}\left(r-r_{\mathrm{X} 0}\right)^{2}\right)\right] .
\end{aligned}
$$

The subscripts $\mathrm{X}, \mathrm{A} / \mathrm{A}^{\prime}$ are added to different quantities such as $r_{0}, \Delta r$ or $a$ to indicate the electronic state to which they refer. Moreover, $\xi$ denotes the fraction of the "large" molecule in solution, whereas $n_{\mathrm{A} / \mathrm{A}^{\prime}} / n_{\mathrm{X}}$ is the branching ratio of molecules recombining on the $\mathrm{A} / \mathrm{A}^{\prime}$ and X surfaces, respectively.

\subsection{Numerical treatment}

The Morse potentials are different in the electronic states $\mathrm{X}$ and $\mathrm{A} / \mathrm{A}^{\prime}$ of $\mathrm{I}_{2}$, as are also the parameters $D, b$, and $\tau_{v}$ describing them. The values of $D$ and $b$ were taken from the literature data for the $\mathrm{X}, \mathrm{A}$, and $\mathrm{A}^{\prime}$ states of $\mathrm{I}_{2}$ [15]. To determine the parameter $b$, the relation $\omega^{2}=(2 D / \mu) b^{2}$ was employed with the frequency $\omega$ taken from [15]. Moreover, the "compact" state $\mathrm{A} / \mathrm{A}^{\prime}$ was described writing $D_{\mathrm{A} / \mathrm{A}^{\prime}}=(1 / 2)\left[D_{\mathrm{A}}+D_{\mathrm{A}^{\prime}}\right]$ and $b_{\mathrm{A} / \mathrm{A}^{\prime}}=(1 / 2)\left[b_{\mathrm{A}}+b_{\mathrm{A}^{\prime}}\right]$. We then found $b_{\mathrm{X}}=1.91 \AA^{-1}$ and $b_{\mathrm{A} / \mathrm{A}^{\prime}}=2.22 \AA^{-1}$. Finally, the equilibrium I-I distance $r_{0}$ was taken equal to $2.5 \AA$ for $\mathrm{I}_{2}$ in the state $\mathrm{X}$, and to $3.1 \AA$ for $\mathrm{I}_{2}$ in the state $\mathrm{A} / \mathrm{A}^{\prime}$.

The remaining parameters were determined using standard mean square procedures. Static parameters were all optimized simultaneously, fitting the observed signals at $t=400 \mathrm{ps}$, where dynamical contributions to $\Delta S[r, t]$ are negligible; a "NonlinearFit" program of Maple was employed for that purpose. From the other side, the parameters describing dynamical processes being all located under the integration sign - were optimized separately from one another. Residual sums of squares were calculated and were divided by the number of degrees of freedom. About 10 iterations were required each time to reach the accuracy which was desired. As a large number of $r, t$ points (about $40 \times 40$ ) were considered, fast integration methods were necessary to realize the optimization process under good conditions. The reliability of this model can be judged noticing that 9 parameters were optimized to fit $40 \times 40=1600$ experimental points with a very good accuracy.

\section{Results and Discussion}

\subsection{Experimental and theoretical signals $\Delta S[r, \tau]$}

The experimental (convoluted) signals $\Delta S[r, \tau]$ will now be examined for the time delays from $-40 \mathrm{ps}$ to $400 \mathrm{ps}$. Considered as functions of $r$, these curves exhibit two peaks, a negative peak at $r=2.5 \AA$, and a positive peak at $r=3.1 \AA$ (Fig. 3). The negative peak comes from the depletion of the $\mathrm{X}$ state, the positive one from the population of the $\mathrm{A} / \mathrm{A}^{\prime}$ state. Note that the signals $\Delta S[r, \tau]$ first appear at negative $\tau$ 's around $40 \mathrm{ps}$. On the other hand, considered as functions of $\tau$, the signals $|\Delta S[r, \tau]|$ first increase up to around $50 \mathrm{ps}$ and then decrease again (Fig. 4). No significant peak shifts in $\Delta S[r, \tau]$ were observed in our experiments. At times longer than 400 
ps, our new signals coincide with those measured in our earlier work $[7,8]$.

These findings are now interpreted theoretically. The signals $\Delta S_{\text {inst }}[r, t]$ were first calculated as described above and were convoluted with the 100-ps x-ray pulses $I_{x}(t)$. The results reached in this way were then compared with experiment. They prove the existence of two signal-shaping mechanisms. (1) The finite pulse width is responsible for the appearance of x-ray signals at negative delays. (2) The recombining I-I motions represent the second signal shaping mechanism. In fact, if the times $\tau_{\alpha}$ and $\tau_{\beta}$ are comparable to the instrumental resolution $\Delta \tau$ as it is the case here, this mechanism generates the rise and the fall of $|\Delta S[r, \tau]|$ illustrated in Fig. 4. A higher resolution would be required to detect peak shifts in $\Delta S[r, \tau]$ directly. On the other hand, we also checked that the above-mentioned temporal variations of $|\Delta S[r, \tau]|$ vanish at lower temporal resolutions entirely. Effects of a similar nature have been reported in other fields of physics; they are known under the general name of motional narrowing [16]. An excellent agreement between theory and experiment should be emphasized. It strongly supports the above interpretation.

In the Table, we present the parameters characteristic of the I-I recombination. They were extracted either from x-ray or from optical studies. The quantities $\tau_{v \mathrm{X}}$ and $\tau_{v \mathrm{~A} / \mathrm{A}^{\prime}}$ represent the I-I recombination times in the electronic states $\mathrm{X}$ and $\mathrm{A} / \mathrm{A}^{\prime}$, respectively. In turn, $n_{\mathrm{A} / \mathrm{A}^{\prime}} / n_{\mathrm{X}}$ designates the ratio of molecules following the $\mathrm{A} / \mathrm{A}^{\prime}$ and the $\mathrm{X}$ reaction channels. Finally, $b_{\mathrm{X}}$ and $b_{\mathrm{A} / \mathrm{A}^{\prime}}$ are the constants of the Morse potentials in the above two electronic states; they are simply related to the corresponding fundamental frequencies of $\mathrm{I}_{2}$.

\subsection{Comparison of the results of $x$-ray and optical studies}

Images of the $\mathrm{I}_{2}^{*} \rightarrow \mathrm{I}_{2}$ recombination in $\mathrm{CCl}_{4}$ provided by the present time-resolved $\mathrm{x}$-ray and by the earlier timeresolved optical studies will now be compared to each other. The present study confirms the presence of two reaction channels located in the electronic states $\mathrm{X}$ and $\mathrm{A} / \mathrm{A}^{\prime}$, respectively (Fig. 5). This feature of the iodine recombination is thus confirmed by both these techniques.

\begin{tabular}{c|ccc}
\hline & X-ray diffraction data & Spectroscopic data \\
\hline$\tau_{v \mathrm{X}}$ & $130 \mathrm{ps}$ & $150 \mathrm{ps}$ \\
$\tau_{v \mathrm{~A}} / \mathrm{A}^{\prime}$ & $4 \mathrm{ps}$ & $<10 \mathrm{ps}$ or $<30 \mathrm{ps}$ \\
$n_{\mathrm{A} / \mathrm{A}^{\prime}} / n_{\mathrm{X}}$ & $70 \%$ & $40 \%$ \\
$b_{\mathrm{X}}$ & $1.9 \mathrm{~A}^{-1}$ & $1.9 \mathrm{~A}^{-1}$ \\
$b_{\mathrm{A} / \mathrm{A}^{\prime}}$ & $2.2 \mathrm{~A}^{-1}$ & $2.2 \mathrm{~A}^{-1}$ \\
\hline
\end{tabular}

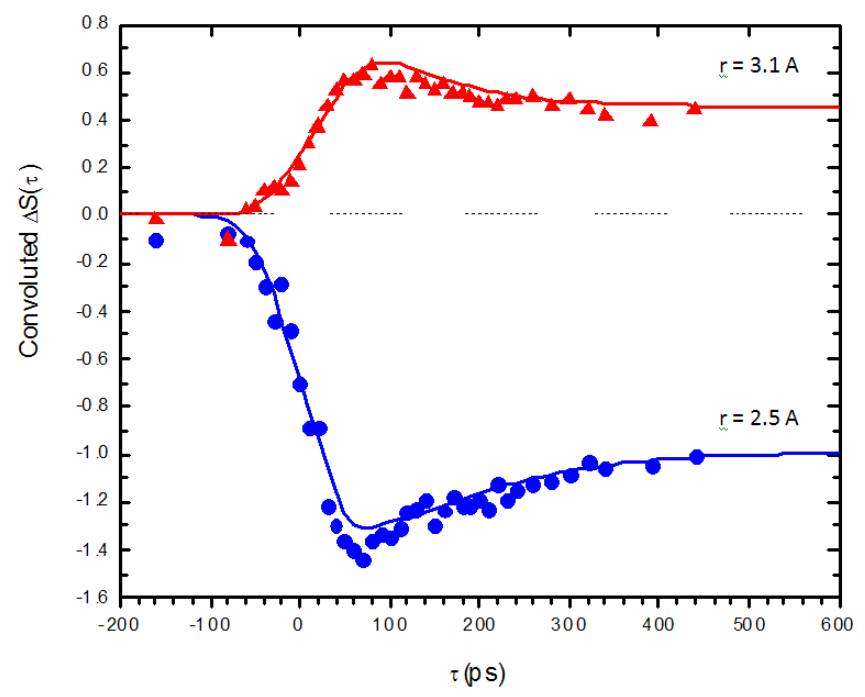

Fig. 4. Time-resolved x-ray signals $\Delta S[r, t]$. They are shown as functions of time $t$ for two distances $r=2.5 \AA$ and $3.1 \AA$. The points represent the experimental data, and the full curves are theoretical ones. The rise and fall of these signals with $t$ represent a fingerprint of the recombination dynamics at a medium time resolution

(A/A')

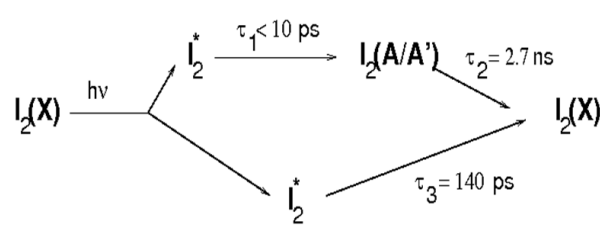

(X)

Fig. 5. Chemical symbols describing the iodine recombination

Moreover, the parameters describing it are similar; compare with data contained in Table. For example, an Xstate vibrational relaxation time $\tau_{v \mathrm{X}}=130 \mathrm{ps}$ is found here, while the inverse rate constant $k_{\mathrm{X}}^{-1}=150 \mathrm{ps}$ was reported in spectroscopic studies [9]. The corresponding values for the $\mathrm{A} / \mathrm{A}^{\prime}$ state are $\tau_{v \mathrm{~A} / \mathrm{A}^{\prime}}=4 \mathrm{ps}$ and $k_{\mathrm{A} / \mathrm{A}^{\prime}}^{-1}<10$ ps [9] or $k_{\mathrm{A} / \mathrm{A}^{\prime}}^{-1}<30$ ps [17]. The comparison is less precise in this case, but the results remain compatible with each other. On the contrary, the occupancies of the two reaction channels are different. The $\mathrm{A} / \mathrm{A}^{\prime}$ pathway dominates in our studies with $70 \%$ occupancy as compared with $40 \%$ in optical spectroscopy [17]. In spite of these differences, it can be stated that $\mathrm{x}$-ray diffraction and optical spectroscopy provide a similar description of the iodine kinetics. Note that this result was reached with experimental technologies which widely differ from each other. 


\section{Conclusions}

Time-resolved x-ray diffraction and absorption have made important progress in the past decade. Synchrotron-based x-ray sources attain currently time scales of the order of 100 ps, whereas the new XFEL sources will reach subpicosecond time scales routinely. This made possible the direct detection and assignment of ultrafast structures during the course of photophysical, chemical, or biological processes. Time-resolved x-ray experiments may also provide real time snapshots of temporally evolving molecular structures. No doubt, this movement in the direction of short times will continue in the next future.

This research was presented at the 5th International Conference "Physics of Liquid Matter: Modern Problems" (Kyiv, Ukraine, 2010), http://www.plmmp.org.ua.

1. Y.R. Shen, The Principles of Nonlinear Optics (Wiley, New York, 1984).

2. C. Bressler and M. Chergui, Chem. Rev. 104, 1781 (2004).

3. S. Bratos and M. Wulff, Adv. Chem. Phys. 137, 1 (2008).

4. M. Chergui and A. H. Zewail, Chem. Phys. Chem. 10, 28 (2009).

5. F. Schotte, M. Lim, T.A. Jackson, A.V. Smirnov, J. Soman, J.S. Olson, G. Phillips, jr., M. Wulff, and P.A. Anfinrud, Science 300, 1944 (2003).

6. M. Cammarata, M. Levantino, F. Schotte, P.A Anfinrud, F. Ewald, J. Choi, A. Cupane, M. Wulff, and H. Ihee, Nature Methods 5, 881 (2008).

7. A. Plech, M. Wulff, S. Bratos, F. Mirloup, R. Vuilleumier, F. Schotte, and P.A. Anfinrud, Phys. Rev. Lett. 92(12), 125505 (2004).

8. M. Wulff, S. Bratos, A. Plech, R. Vuilleumier, F. Mirloup, M. Lorenc, Q. Kong, and H. Ihee, J. Chem. Phys. 124(3), 034501 (2006).

9. A.L. Harris, J.K. Brown, and C.B. Harris, Ann. Rev. Phys. Chem. 39, 341 (1988).
10. F. Schotte, S. Techert, P.A. Anfinrud, V. Srajer, K. Moffat, and M. Wulff, Third-Generation Hard X-ray Synchrotron Radiation Sources (Wiley, New York, 2002).

11. M. Cammarata, M. Lorenc, T.K. Kim, J.H. Lee, Q.Y. Kong, E. Pontecorvo, M. Lo Russo, G. Schiró, A. Cupane, M. Wulff, and H. Ihee, J. Chem. Phys. 124(12), 124504 (2006).

12. S. Bratos, F. Mirloup, R. Vuilleumier, and M. Wulff, J. Chem. Phys. 116(24), 10615 (2002).

13. M. Ben-Nun, Jianshu Cao, and Kent R. Wilson, J. Phys. Chem. A 101(47), 8743 (1997).

14. R. Neutze and R. Wouts, J. of Synchr. Rad. 7, 22 (2000).

15. Y.P. Varshni, Can. J. Chem. 66, 763 (1988).

16. A. Abragam, Les Principes du Magnétisme Nucléaire (Univ. de France, Paris, 1961).

17. D.F. Kelley, N.A. Abul-Haj, and Du-Jeon Jang, J. Chem. Phys. 80(9), 4105 (1984).

Received 21.01.11

ВІЗУАЛІЗАЦІЯ ХІМІЧНИХ РЕАКЦІЙ

РЕНТГЕНІВСЬКИМ ВИПРОМІНЮВАННЯМ

С. Братос, М. Вулф, ЖК.-К. Лейкнем, Р. Вулемъе,

K. Рожансъка

Р е $з$ ю м е

Методом дифракції рентгенівських променів з розподілом у часі досліджено рекомбінацію молекул йоду, що розчинені в $\mathrm{CCl}_{4}$, після дисоціації їх лазером. Імпульси рентгенівських променів отримано на синхротроні Європейського центру синхротронного випромінювання у Греноблі. Внесок розчинника у вимірювальні сигнали виключений застосуванням відповідної методики. Рух атомів йоду досліджено у часі від 200 до 10 пс. Показано наявність різних релаксаційних процесів у цьому проміжку часу. Доведено, що рекомбінація іде двома шляхами в електронні стани $\mathrm{X}$ та $\mathrm{A} / \mathrm{A}^{\prime}$ молекули $\mathrm{I}_{2}$ відповідно. Незважаючи на різні експериментальні методики, що використовують лазерне і рентгенівське випромінювання, вони дають схожі картини цієї реакції. 